\title{
Classification of Travelers for the Recommendation of Suitable Integrated Multimodal Services
}

\author{
Reuben Joshua S. Kaura, Panos Georgakis
}

\begin{abstract}
This paper presents limitations of existing congestion management techniques which are attributed to the absence of robustness, coordination among traffic control elements and lack of adaptation in the current method to the changing traffic circumstance. The aim is to use clustering analysis in the area of machine learning to identify and develop classifiers that possibly "classifies" the types of transportation users, including travelers driving a car, riding a bicycle, riding a bus, taking a taxi and hiring a private car; which involves grouping the traveler as a driver or a passenger. For this study, statistical and analytical methods of distinguishing variations in the preferences of mode choice among the commuters was applied on a secondary data feedback collected from Birmingham city council. Euclidean distance is a clustering algorithm that was considered as attribute model, which includes distance algorithms i.e. distance between points and distributions models. Nine (9) questions and answers from the feedback were selected and modified for the statistical clusters modeling and the $K$ means algorithms was used in the clustering process. The result from the analysis was exported out in excel format in which the data of travelers was categorized mainly into two groups (Drivers / Passenger), which was further used to classify individual traveling behaviours. Certain rules were set identify types of Drivers and Passengers, persuadable and non-persuadable. These categories were further used to classify individual traveling behaviors. Certain rules were set to identify types of Drivers and Passengers, persuadable and non-persuadable.
\end{abstract}

Keywords : Classification of travelers, Cluster Analysis, Congestion Management, Travel Behaviours, Description of types of travelers.

\section{INTRODUCTION}

In transportation, mobility providers waste a lot money and resources in dispatching information to the public as most of the information doesn't meet its targeted audience, therefore it doesn't meet the consumers' needs. Their strategy of the method of dispatching information does not effectively help in improving and reducing transportation, congestion etc. Therefore, classifying transportation users in-to classes/groups helps in the dispatching of the right information to the right audience even at the right time. This can be used to improve transportation as a service, reduce the use of private cars, increase the use of public transportation and facilities such as park and ride and reduce congestion in the transportation sector.

The high level of congestion on European Transport networks can be attributed to private vehicles. EU statistics (EUROSTAT, 2006) show that the number of cars in the

\footnotetext{
Revised Manuscript Received on September 10, 2019.

Reuben Joshua S. Kaura, Science and Engineering/Built Environment, University of Wolverhampton, Wolverhampton, United Kingdom.

(Email: kaurareuben@gmail.com)

Dr Panos Georgakis, Science and Engineering, University of Wolverhampton, Wolverhampton, United Kingdom.

(Email: P.Georgakis@wlv.ac.uk)
}

EU25 (25 countries) increased by nearly $40 \%$ between the 1990 and 2004. In the course of the period of 1995-2004 passenger transport demand/use for private cars increased by $17.7 \%$ in comparison to minor increases in the use of railways $(8.6 \%)$, buses and coaches $(5.8 \%)$. Whereas EU statistics (EUROSTAT, 2015) show that in 2013, the dependence on cars for passengers was highest, which had more than 500 passenger cars for every 1000 inhabitants From the above, the public's increasing shift towards private cars as the primary means of transportation as opposed to collective means is evident. However, limitations of existing congestion management technique are attributed to:

- Absence of robustness and self-sufficiency because of centralized control

- Absence of coordination: The absence of coordination among traffic control elements (e.g. uncoordinated traffic signs, uncoordinated traffic flow of public and private modes) averts worldwide perspectives of traffic state.

- Absence of adaptation: Many of the current methods can't adjust rapidly to the changing traffic circumstance. The data processing and data dispersal time is so high there is no time to reflect the real-time traffic circumstance.

A constant attribute of limitation in transportation is the absence of the ability to monitor/manage and predict human transportation behaviours as they are constantly changing due to circumstances presented to travels either individually or collectively. Therefore, detail understanding of the reason for choosing one mode over another and travel behavior attempts addressing the issue of unsustainable pattern of travel. Psychological factors such as social norms, identity, perceptions and habits have proven useful in understanding travel mode choice (Bamberg and Schmidt, 2001; Steg et al., 2001; Stradling et el., 1999). This is often disregarded in travel research policy interventions and methodology, on the contrary the combination of instrumental, situational and psychological factors influences the travelers' choice of mobility service and transport mode. Although, more and more high-level research and analysis on travel behavior is providing better insight of mode choice, the surveyed populations sample are rarely grouped using their perspective, motive and mental views. Wherever segmentation transpires, it is customarily based on a priori (presumptive) social demographic classifications and not on the footing of a more statistically complex derived clusters 
of characteristics. Wedel and Kamakura (1998), states that it is standard practice in the study of marketing and customer behaviour to distinguish homogenous groups of customers who are targeted in the same fashion because of their similar preferences and needs. The variances amongst travelers shows that travelers must and should be provided for in different ways because travelers are motivated and affected by different policy and factors.

The aim of this paper is to review existing research and examines statistical and analytical methodologies that can be used in identifying and classifying these variances of travelers into meaningful groups in a statistical and psychological sensible approach. In this paper a review of related studies from previous research such as travel behavior, traveler's mode choice and segmentation practices of which classification methods like clustering analysis was evaluated. By using a UML tool, a conceptual view was developed to support system development where it explains the relationship and flow of information of the proposed model. A cluster analysis was performed on the data survey acquired and from the result extract and export to excel, the data was categorised into two groups namely drivers and passenger. A further analysis was conducted in excel leading to further sub categorizing of the groups and a description of these groups was presented.

\section{REVIEWS}

\section{A. Related Works}

Although, there is no scarcity of research studies attempting to identify typical characteristics of travelers travel behaviour, there is insufficient literature studies that defines different segments of mobility users in a systematic and demographic significant view (Brindle, R. E. 1994; Frank, L. D. and Pivo, G. 1994; Stokes, 1996 Curtis and Headicar, 1997; Taylor and Brook, 1998; Wardman et al., 2001; Bertolini and Dijst, 2003; Dimitriou, 2013; Coppola et al., 2014; Kosonen 2015). Apparently, the inclination of travelers switching between modes has instigated some mobility issues such as the nature and source of car dependent attitude hence made several studies use psychology for the study of mode choice (Bamberg and Schmidt, 2001; Steg et al.,2001; Donald IJ, Cooper SR, Conchie SM, 2014; An S, Wang Z, Cui J 2015; Lind HB et al 2015; Heinen, Eva 2016). These theories and views are effective at enabling the bridge to understand the nature of travelers, such as travelers with a bond to cars and the point to which individuals' sense difficulty to change.

In general, researches in this field apply merging concepts of behaviour including more elusive collections of hypotheses for the analysis of car ownership and its use. Previous studies have showed the significant affective motives such as "social and pleasure comparisons" which are incredibly relevant as "traditional-reasoned motives for example the time and cost for the car usage (Steg et al 2001). Gatersleben and Uzzell (2003), in the same way recommended that affective motives may perhaps appear to be of more importance for travel mode choice than cognitive elevations in some circumstances. Garling (1998), attempted to find a connection between choices and psychologically significant motivational conceptions such as moral obligation and happiness; while Stradling et al. (2000) established, that travel decisions are determined by the interaction of 'opportunity', 'obligation' and 'inclination'.

Bamberg and Schmidt (1998) and Forward (1998), revealed that most of these researches established that the choice of travel mode is generally a reasoned decision associated specifically to attitudes and perceived barriers to behaviour. Ajzen (1991), also showed that various studies applied the psychological theories of attitude-behaviour relations like the theory of planned behaviour (TPB) for predicting or identifying mode choice. Though other studies imply a lot of travelers' day-to-day transport mode choice are customary rather than preceded by planning and consideration of the alternative choices. Verplanken et al., (1994), Garling et al., (2000), Bamberg et al., (2003), advocate the inclusion of a quantitative measure of habit will enhance the identifying and prognostic capability of attitude-behaviour studies.

Van Vugt et al., (1995), and Steg and Vlek, (1996), showed transport-related issues are regularly interpreted by psychologists as 'commons dilemmas. Research papers regarding several transport policy measures show how individuals are more willing to consent to positive measures (pull) rather than negative measure (push) (Steg and Vlek, 1997; Schade and Schlag, 2003; Friman M. et al 2013; Alonso A, Monzón A, Wang Y, 2017). Furthermore, the commons dilemma indicates a divergence between "long term" collective interests and "short term" individual interest. The finding from these reviews implies that in accumulation of several intellectual opinions, key elements which induces individual's choice of transport involves social value orientation, perceived effectiveness, personal norms, trust in the co-operative behaviour of others and the sense of responsibility, Anable J. (2005) studies advocates these beliefs.

\section{B. Segmentation Practices}

Ultimately, describing segmentation from both marketing and research point of view, as explained by Wedel and Kamakura (1998) and Hair et al., (1998) in simple terms is basically the conduct of distinguishing significant subgroups of objects or individuals. The fundamental of segmentation is decreasing the number of objects being distributed amongst a manageable set of genres which are mutually exclusive and encompass very good termed features. Immediately the clusters(groups) are identified, classification becomes possible via their responses to variety of conditions. While the aim of segmentation is greatly acknowledged, the assortment of techniques used to accomplish it implies 'segmentation' encompasses an assortment of methodologies. Green and Krieger (1995), basically stated that, these methodologies can be divided into two (2), which are;

1) A priori, whereby groups are chosen from a populace ahead of time in view of established attributes and pronounced as "segments" such as socio-demographic qualities or frequency of vehicle utilization.

Published By: 
2) Post hoc, whereby pragmatic examination utilizing some type of multivariate statistical investigation is utilized to classify segment.

In this latter method, the respondents are classified by their likeness on multivariate profiles on any number of blends of factors. These may incorporate different blends of, for instance, attitudinal, behavioral or personality attributes. Above all, past the underlying decision of base factors, the segments are dictated by the information, not the specialist, and the quantity of clusters and their relative size is not known until the point when the procedure has been finished. The a priori methodology has been almost solely utilized in travel behaviour studies. Fundamentally, segmentation schemes generally utilized within transport planning are often for the clear majority in predefined key sociodemographic factors like car ownership, wages and sexual orientation or rather behaviour qualities for instance, the constancy of use of a transport mode such as (higher user vs lower user). Methods such as regression analysis are frequently utilized for illustrating the affiliations between sets of independent factors and segment associates. The value of market segmentation analysis for transport services was exhibited by distinguishing various probable segments with comparable behaviors towards the characteristics of each transport mode (Pas and Huber, 1992).

This study indicated the complication of the travel market and the feasible benefits of describing segments of the people in relation with the benefits they want and anticipate from utilizing different methods of transport. Davies et al., (1997) utilized target gatherings to distinguish groups of cyclists in view of characteristics to this method of travel. This study established that segmentation on the premise of characteristics empowers the presumption of persona, status and constraints to detected in each group. Jensen (1999), utilized qualitative information from detailed interview to detect six types of mobility, which included three private vehicle driving segment such as (enthusiastic, ordinary and leisure time car drivers) and three public transport segments were (users of the heart, users of convenience and users of necessity).

Because some of these studies based on segmentation endeavor to detect the individuals who are well on the way to change behaviour, they share similar goals with the research which shapes the aim and composition of this paper. In spite of this, the current research diverges from these studies given that they don't utilize statistical systematic segmentation approaches which utilizes psychographic and attitudinal factors that has been obtained from evaluations such as surveys, interview and questionnaires, neither do they specify the traveler's persona. Psychographic is the study and classification of people according to their attitudes, aspirations, and other psychological criteria, especially in market research. Gotz (2003), however utilizes the idea of 'mobility styles' by utilizing the techniques used for attitudinal and lifestyle research to classify the following five segments; (i) the traditional domestic; (ii) reckless car fans; (iii) the status oriented automobilists; (iv) the traditional nature lovers; (v) the ecologically resolute; which Gotz also argues that determining ecological outcomes like $\mathrm{CO} 2$ emissions is

achievable by calculating according to particular focused groups or clusters.

Clusters analysis is a common technique for statistical data analysis in data mining used for exploratory tasks used in many fields, including machine learning, marketing, medicine, ecology, law and many more However, it can also provide recommending that can lead to the reduction of private car usage and increase public mode transport and share ride which in turn would reduce congestion in the transport sector.

This paper is aimed at addressing the research gaps mentioned in this review such as the absence of robustness and coordination of control elements, absence of adaption of the rapidly growing changing traffic circumstances and most importantly the absence of the ability to monitor / management and predict human travel behaviours.

\section{METHODOLOGY}

\section{A. Research Background}

For this study the use of statistical and analytical methods of distinguishing variations in preferences of mode choice among the travelling population was applied on a secondary data feedback collected from Birmingham city council. Although the data contains several segments, this study focuses on the travel activities segments because of the vast data and limited time allocated for the project, even though the methods and principles adopted can correspondingly be applicable to all segments. The transport study feedback data survey from Birmingham city council consisted of 1001 participants, 243 variable labels and 3980 variable values. The study uses empirical and theoretical derived demographic attributes variables of travelers and data analysis \& market segmentation techniques to identify groups of travelers regarding their mode of travel choices.

Decreasing the waste of money and resources by improving the dispatching of information adequately which will help in the reduction of congestion is target we aim to achieve. The clustering algorithms that were considered are attribute models, which includes distance algorithms i.e. distance between points (Euclidean distance), probably the most common are the centroid based models (distance from centroid), density algorithms (density of points) and distributions or distributional models. For the statistical clusters modeling, secondary data of transportation feedback from survey acquired was modified for clustering analysis. The K-means algorithms function was used to derive our centroids in the clustering process. The data survey acquired provided significant information to distinguish between transportation users/travelers. The centroid based model and the distribution modeling methods was found to produce the best and preferred analysis due to the attributes such as handling large data, providing an easy understanding of the analysis process and results, being able to provide analysis with the required number of clusters we specified. One major advantage is that, it is good at capturing the correlations or interrelations between the attributes in our 
data which none of the other approaches do specifically. Though there are several categories of algorithms, they all have their different pros and cons. Such as, some only do convex shapes, some do equal size clusters, some are difficult for large data sets, some are hard to describe parametrically and therefore, being mindful of these options we select an algorithm that fits our data and fits the purposes for conducting our pragmatic applications of cluster analysis.

The development of a conceptual view is required thus the strategy purposed is to redirect however many of those that would be prudent, from their private vehicles/modes into the public transport, cycling or walking to reduce congestion. The methodology is to use the survey data of travel activities feedback gathered to analysis traveler in groups, using statistical and analytical methods like clustering. This could encourage encouraged travelers to utilize the transport such as train, bus or bicycle twice in a week which would take up to 200,000 car journeys off the streets (Neil, E. 2014).

\section{B. Conceptual Views}

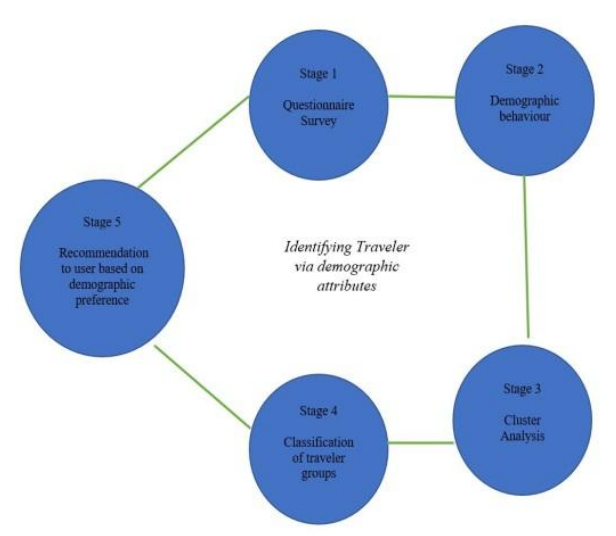

Fig. 1.

\section{Descriptive view}

Figure 1 illustrates the 5 stages of approach for identifying travelers through their demographic travelling behaviours. Stage 1 is analysing the questionnaire and the responses and then stage 2 is identifying the questions and responses that will be used for clustering travelers which leads to stage 3. Cluster analysis is performed at stage 3 and the result is the outcome of stage 4 i.e. identifying and subgrouping travelers from the clustered data. Stage 5 is the final stage which entails mobility services and other suitable services recommended specifically to certain groups with the most suitable and beneficial information.

To develop a system that supports this procedure we intend using the UML to represent the system components and their relationships. The UML tools are widely applied in the development of critical systems as stated by M. Jeckle (2014). The UML is a tool very familiar to the community of software developers and compared to others tools it must be classified as a semi-formal representation and it is well acknowledged as an effective standard in the industry.

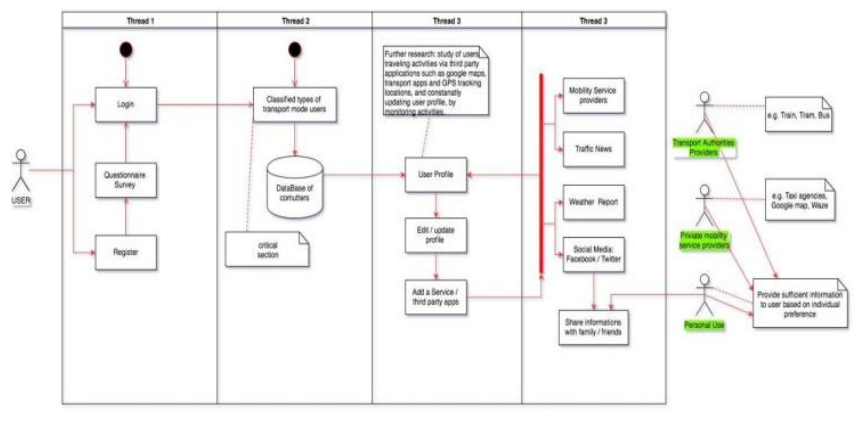

Fig. 2. UML diagram of conceptual system

Fig. 3.

Figure 2 is a UML diagram that explains the relationship and flow of information of the conceptual model. A new user will have to register, complete the survey questionnaire which will automatically login the user. Using clustering analysis and classifying algorithms it then classifies the user in a group based on the user's questionnaire feedback, which is store in a database and saved as the user's profile, whereas an existing user is logged into the database profile. The user has the option of editing their profile and adding a service they would require in assisting / contributing in their daily traveling activities and mode choice. The system provides the user with appropriate information established from the feedback which the user was grouped into, i.e. suitable information is supplied to each group based on their individual group preferences. For instance, a car addict might not be interested in public transport such as train, tram or bus but information about traffic, congestion road closure might make the user reevaluate their plans, and alternatives such as park and ride and carpooling would serve as more suitable alternative. The segmented user system could be linked to or used by transport authority providers, private mobility providers and personal use, where the mobility providers can have a direct link to offering targeted travelers with valuable specified information rather than sending it to everyone. For personal use, if the user is a driver the user can choose to offer or look for carpooling services, park and ride etc. However, depending on what type of Driver or Passenger group the user is classified under, suitable options are passed to the individual groups. Social media functionality is added as well to improve the sharing of information between family and friends as it is one of the most effective means of passing on recommendation.

\section{Clustering}

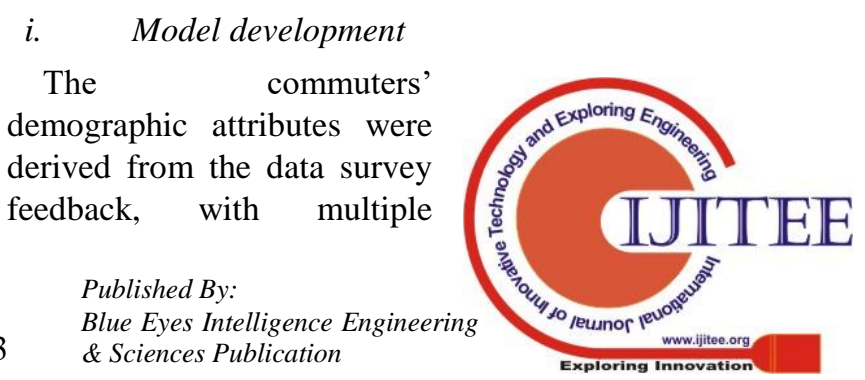


corresponding travel behaviour statements. As stated by Ajzen (1991), previous behaviour is a sign of intentions that shows a repeat of behaviour in the future, however the effect is indirect and is arbitrated by attitudes and subjective norms. In any case, various studies have discovered that habits relate more firmly with intention and behaviour than with different factors in the TPB (Forward, 1994, 1998; Garling et al., 1998; Aarts and Dijksterhuis, 2000). Therefore, nine(9) questions and answers from the feedback were selected, which the purpose of the selected feedback questions is to separate the drivers from the passengers and questions are as follow:

1. How many, if any, cars or vans does your household own or have the regular use of?

2. Are you the main driver of this vehicle/either of these vehicles/any of these vehicles?

3. How often do you usually travel by car or van as a driver?

4. How often do you usually travel by car or van as a passenger?

5. Do you own, or have access to, a bicycle that is in good enough condition for riding?

6. How often do you usually travel from place to place by bicycle?

7. How often do you usually travel... by local bus?

8. How often do you usually travel... by train or tram?

9. How often do you usually travel around Birmingham by taxi or private hire?

These specific questions and feedbacks were extracted from the survey data which is in an excel format then recreated to only contain these specified data and saved in a different secure location as not to interface with the original data. The new data is then imported into $\mathrm{R}$ for $\mathrm{K}$ - Means clustering analysis.

\section{ii. $\quad$ Clustering results review in $R$}

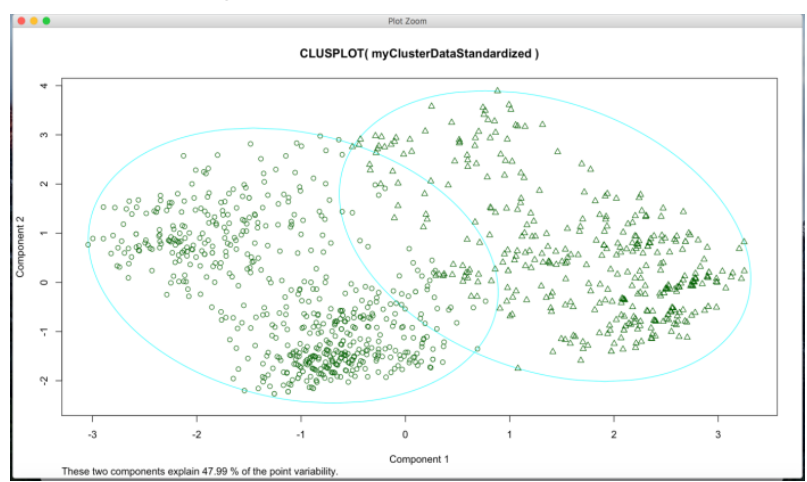

Fig. 4.

K-means clustering of travelers

Figure 3 shows a standardized clustered data of travelers from our Birmingham city council survey feedback. Using selected nine (9) questions we use the k-means algorithms for clustering and setting 2 for our clusters. We choose two (2) for our clusters because we know and are expecting 2 clusters which is Drivers and Passengers. The circle dots in figure 3 represents passengers while the triangles signifies drivers.

It is a common practice that PCA is utilized to project to lower dimensional subspace and K-means is then applied in the subspace (Zha et al., 2002). Similarly, data can be embedded in a low-dimensional space such as the eigenspace of the graph Laplacian, and K-means is then applied (Ng et al., 2001). In this case the components 1 and 2 are the first two principal component analysis (PCA) representing drivers and passengers, in simple terms, principal component analysis is a way of extracting key variables in form of components from a huge set of variables available in a data set. It extracts low dimensional set of features from a high dimensional data set with a motive to capture as much information as possible. With fewer variables, visualization also becomes much more meaningful. PCA is more useful when dealing with 3 or higher dimensional data. Since data can be multivariate, it could be tedious to review all the many bivariate scatterplots. Preferably, a single summarising scatterplot is more appropriate, the scatterplot of the first two (or possibly the first three) principal components which were derived from the data. "47.99\% of the point variability" states that, with the data, almost half of the information about the multivariate data is captured by this plot of components 1 and 2.

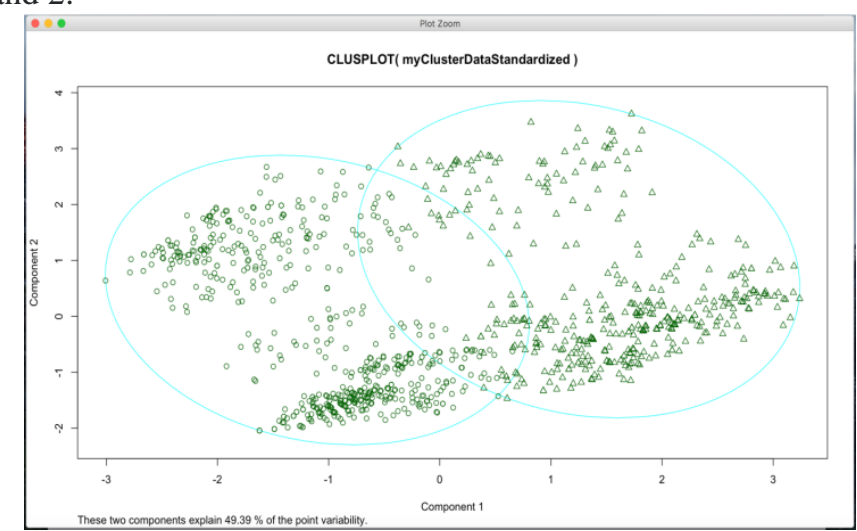

Fig. 5.

K-means clustering of travelers

Figure 4 shows the K-means clustering, however, the PCA has improved from $47.99 \%$ to $49.39 \%$ about $1.4 \%$, this is because the questions in the data that were clustered were 8 instead of 9 question. It dealt with less data hence we see a little bit of improvement in the PCA.

\section{Clustered Groups}

The result of the cluster analysis is exported out in excel format in which the data of travelers is divided into two groups namely: Drivers / Passenger; then the acquired data is used for further classification of individual traveling behaviours. For further analysis in excel, we set certain rules to identify types of Drivers and Passengers which consists of persuadable and non-persuadable travelers. The following are the descriptions of groups in which the rules were set to further categorise and analyse the newly imported data in excel.

\section{DRIVERS}

\section{A. Persuadable Drivers}

\section{$i$. The aspiring environmentalist:}

these are travelers who have already substantially reduced their car usage significantly for mostly environmental and health purposes, but they have genuine reasons for the use and advantages of car travel

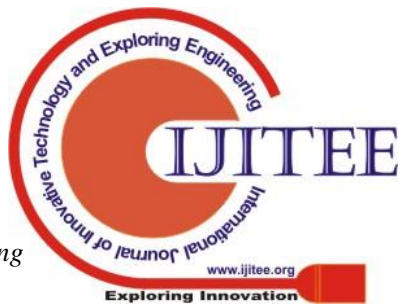


which it offers and therefore are reluctant to relinquish their car ownership completely.

\section{ii. The compliant driver:}

these travelers, on the other hand, are involuntary users of public transport due to health or financial reasons, they are inclined to agree with others or obey rules, and sourcing alternatives routes and modes to meet their current situation needs. They would prefer to travel by car and either aspire to owning a car in the future or accept lifts by car when possible.

\section{iii. The improbable driver:}

these are travelers that assume and say they are most likely to use alternatives and public modes depending on specific demands or alternatives offered in the survey, but it is mostly not likely to be true. Even as some of these alternatives already exist these travelers are not aware of it or do not make use of the alternatives as regular as they thought they would due to either convenience or are accustomed to their mode and method of traveling.

\section{B. Non-Persuadable Drivers}

\section{$i$. The complacent car addict:}

these travelers conversely acknowledge that the use of alternative modes is possible, but do not feel any moral imperative or other incentive to alter their car use. This can be due to the dominance of the car culture and an overall psychological attachment and dependency on the car.

\section{ii. The probable driver:}

these are travelers that probably aspire to own, share ownership or actually - own a car but prefer to use more alternatives modes such as park and ride, share rides, offer rides and accepting lifts from other drivers and as such are happy and satisfied with their current method and means of transportation.

\section{iii. The die-hard driver:}

The die-hard drivers are attached to private cars and are fond of car travel, they believe in the right to drive cheaply and freely and have negative feelings towards all other travel modes. Travelers in this category show exceptionally high dependence on car and low intention to utilize alternative modes.

\section{PASSENGERS \& RESULTS}

\section{A. Persuadable Passengers}

$i$. The environmentalist: these are travelers who have completely stop using and depending on the use of privatecar only for mostly environmental and health purposes. They use and depend mostly on public modes and other alternatives for transportation and therefore they have long happily relinquished their car ownership completely or are reluctant to owning a car.

\section{ii. The probable passenger:}

these are travelers that probably do not aspire to own, share ownership or actually - own a car but prefer to use more alternatives modes such as public modes, walking, bicycling, share rides and accepting lifts from friends and as such are happy and satisfied with their current method and means of transportation - other personal reasons can also be the cause for their choice of transportation methods.

\section{iii. $\quad$ The reluctant passenger:}

these are travelers that are involuntary users of public transport due to health or financial reasons. They would prefer to travel by car, public transport or other alternative depending on their current situation and some of these travelers either aspire to owning a car in the future or accept lifts by car when possible. They would use any alternative means to commute if it fits their present purpose and situation.

\section{B. Non-Persuadable Passengers}

\section{$i$. The Complacent passenger:}

these travelers conversely acknowledge that the use of alternative modes is possible, but moral imperative or other incentive do not contribute to why do not depend on car use nor on a single mode for transport. This can be due to accustomed attachment toward public modes or the persistent trust in the availability of public and alternative means of transport. These travelers are not aware of how they are contributing in the reduction of gas emissions in the transportation section.

\section{ii. $\quad$ The Improbable passenger:}

these are travelers that are already accustomed to maybe a specific type of public mode such as bus, but they however assume and say they are most likely to use alternatives modes depending on specific demands or alternatives offered in the survey but it is mostly not likely to be true. Even as some of these alternatives already exist these travelers are not aware of it or do not make use of the alternatives as regular as they thought they would due to either convenience or are accustomed to their mode and method of traveling. 


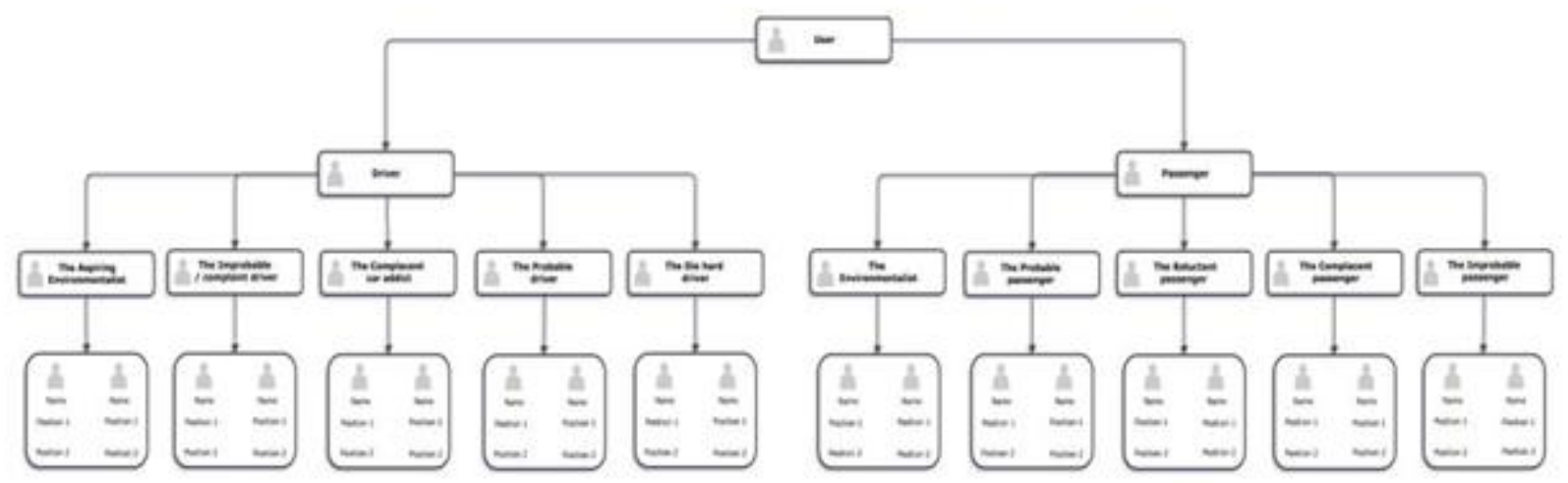

Fig. 6.Diagram of the classification of traveler

\section{DISCUSSION AND CONCLUSION}

Certainly, the benefit of travel behavior graph is not limited to obtaining attribute indexes of different travel users such as passengers. The segmentation and graph methods can show a complete individual travel behavior instinctively, and it weigh in on judging the travel behavior's comparison and variance amongst diverse passengers. In addition, travel behavior depends on computer support, these diagrams can be used for advance intelligent applications (e.g., identifying, forecasting, and reasoning) when integrated with other methods such as deep learning.

The work described in this paper has been initiated by the need of a classification solution for the data acquired from the transport study feedback data survey from Birmingham city council and used for the travel behaviour study. We have described a conceptual view and have also implemented it. the dataset is now classified with a significantly higher accuracy than the existing (semimanual) methods. For travel behaviour research, we believe our method and our theoretical review of clustering methods is also useful in other disciplines since it can be easily extended with new transportation modes. Moreover, the method is universal, and we had shown it works for data collected with any modern devices and methods.

Although it is very difficult to consider all possible cases in the real-world, the model produced suitable outcomes, particularly in the segmentation and classification of data containing a small figure of samples. Normally, what may look like errors are rather specific situations in which in the process of modelling it became complicated because it is may not be possible to consider virtually all circumstances in travel behaviour.

Conclusively, we cogitate that an improved classification could be attained if a more required specified data about the users is used. Subsequently a user's travel habits ordinarily comprise of recurring journeys, not only in space but also in time and frequently with similar transportation mode(s) such as daily commuting. Therefore, a user's historical data can be sourced towards advancing the classification in unknown circumstances. It should be possible to facilitate the classification of users via searching for similar patterns and use of mobility mode(s) and service(s) of users from a group of similar behavioural habits in the database to predict, recommend and assigning multimodal modes and mobility services.

\section{REFERENCES}

1. Aarts, H., Dijksterhuis, A., 2000. Habits as knowledge structures: automaticity in goal-directed behaviour. Journal of Personality and Social Psychology 78 (1), 5363.

2. Ajzen, I., 1991. The theory of planned behaviour. Organisational Behaviour and Human Decision Processes 50, 179-211.

3. Anable J. 'Complacent Car Addicts' or 'Aspiring Environmentalists'? Identifying travel behaviour segments using attitude theory. Transport Policy. 2005;12(1):65-78.

4. Alonso A, Monzón A, Wang Y. Modelling Land Use and Transport Policies to Measure Their Contribution to Urban Challenges: The Case of Madrid. Sustainability. 2017;9(3):378.

5. An S, Wang Z, Cui J. Integrating Regret Psychology to Travel Mode Choice for a Transit-Oriented Evacuation Strategy. Sustainability. 2015

6. Bamberg, S., Schmidt, P., 1998. Changing travel mode choice as rational choice: results from a longitudinal intervention study. Rationality and Society 10, 223-252.

7. Bamberg, S., Schmidt, P., 2001. Theory-driven evaluation of an interven- tion to reduce the private caruse. Journal of Applied Social Psychology 31 (6), 13001329.

8. Bamberg, S., Ajzen, I., Schmidt, P., 2003. Choice of travel mode in the theory of planned behavior: the roles of past behavior, habit, and reasoned action. Basic and Applied Social Psychology 25, 175-188.

9. Bonoma, T.V. and Shapiro, B.P. (1984), "Evaluating market segmentation approache", Industrial Marketing Management, Vol. 13 No. 4, pp. 257-268.

10. Brindle, R. E. (1994), 'Lies damned lies and automobile dependence' (paper delivered to the 19th Australian Transport Research Forum, Lorne, 1994).

11. Christopher, M., Mena, C., Khan, O. and Yurt, O. (2011), "Approaches to managing global sourcing risk", Supply Chain Management: An International Journal, Vol. 16 No. 2, pp. 67-81.

12. Cooil, B., Aksoy, L. and Keiningham, T.L. (2008), "Approaches to customer segmentation", Journal of Relationship Marketing, Vol. 6 Nos 3/4, pp. 9-39.

13. Davies, D.G., Halliday, M.E., Mayes, M., Pockock, R.C., 1997. Attitudes to cycling a qualitative study and conceptual framework. Transport Research Laboratory 1997; ref. 266. 
14. DIMITRIOU, H. (2013) [1992], Urban Transport Planning: A Developmental Approach, London, Routledge.

15. Donald IJ, Cooper SR, Conchie SM. An extended theory of planned behaviour model of the psychological factors affecting commuters' transport mode use. Journal of Environmental Psychology. 2014

16. Eurostat. (2015). Eurostat regional yearbook 2015. Luxembourg: Publications Office of the European Union.

17. Forward, S.E., 1994. Theoretical Models of Attitudes and the Prediction of Driver's Behaviour. Uppsala Psychological Reports 343, Uppsala University, Sweden.

18. Forward, S.E., 1998. Behavioural Factors Affecting Modal Choice: ADONIS. Swedish National Road and Transport Research Institute, Sweden.

19. FRANK, L. D. and PIVO, G. (1994), 'Impacts of mixed use and density on utilization of three modes of travel: single-occupant vehicle, transit and walking', Transportation Research Record, 1466, 44-52.

20. Friman M, Larhult L, Gärling T, Karlstads universitet, Fakulteten för ekonomi, kommunikation och IT, SAMOT. An analysis of soft transport policy measures implemented in Sweden to reduce private car use. Transportation. 2013;40(1):109-29.

21. Garling, T., Gillholm, R., Garling, A., 1998. Reintroducing attitude theory in travel behavior research. The validity of and interactive interview procedure to predict car use. Transportation 25, 129-146.

22. Garling, T., Boe, O., Fujii, S., 2000. Empirical tests of a model of automobile choice incorporating $S$

23. Gattorna, J. (2010), Dynamic Supply Chains: Delivering Value Through People, Pearson Education Limited, Harlow.

24. Gotz, K., 2003. A research concept for mobility styles. Paper Presented at 10th International Association of Travel Behaviour Research Tri- Annual Conference, Lucerne, 10-15 August.

25. Green, P.E., Krieger, A.M., 1995. Alternative approaches to cluster-based market segmentation. Journal of the Market Research Society 37 (3), 221-239.

26. Hair, J., Anderson, R., Tatham, R., Black, W., 1998. Multivariate Data Analysis, Fifth ed Prentice Hall, Englewood Cliffs, NJ.

27. Heinen E. Identity and travel behaviour: A crosssectional study on commute mode choice and intention to change. Transportation Research Part F: Traffic Psychology and Behaviour. 2016

28. Jensen, M., 1999. Passion and heart in transport a sociological analysis on transport behaviour. Transport Policy 6, 19-33.

29. KOSONEN, L. (2015), 'The three fabrics strategy in Finland', in H. Barton, S. Thompson, M. Grant and S. Burgess (eds), Planning for Health and Well-Being: Shaping a Sustainable and Healthy Future, London, Routledge.

30. Lind HB, Nordfjærn T, Jørgensen SH, Rundmo T. The value-belief-norm theory, personal norms and sustainable travel mode choice in urban areas. Journal of Environmental Psychology. 2015

31. Neil Elkes. 20-year transport vision for city mapped out: Pounds 4bn strategy to get Birmingham moving published by the council. Birmingham Post. 2014.

32. Ng, A., Jordan, M., \& Weiss, Y. (2001). On spectral clustering: Analysis and an algorithm. Proc. Neural Info. Processing Systems (NIPS 2001).

33. M. Jeckle. http://www.jeckle.de/umltools.htm (accessed on 2014)

34. Office for Official Publications of the European Communities. (2007). Eurostat yearbook, 2006-07.

35. Pas, E., Huber, J.C., 1992. Market segmentation analysis of potential rail travelers. Transportation 19, 177-196.
36. Schade, J., Schlag, B., 2003. Acceptability of urban pricing strategies. Transportation Research Part F 2003 $45-61$.

37. Steg, L., Vlek, C., 1996. Car use as a social dilemma: conditions for behavioural change in reducing the use of motor vehicles. Paper Presented to Annual PTRC European Transport Conference.

38. Steg, L., Vlek, C., 1997. The role of problem in awareness willingness-to- change car use and in evaluating relevant policy measures. in Rothengatter, T., Carbonell, V.E., (Eds.) pp. 465-475.

39. Steg, L., Vlek, C., Slotegraaf, G., 2001. Instrumentalreasoned and symbolic-affective motives for using a motor car. Transport Research Part F 4, 151-169.

40. Stokes, G., 1996. Getting commuters onto public transport-a survey in Merseyside. Paper Presented to Annual PTRC European Transport Conference.

41. Stradling, S.G., Meadows, M.L., Beatty, S., 2000 Helping drivers out of their cars: integrating transport policy and social psychology for sustainable change. Transport Policy 7, 207-215.

42. Van Vugt, M., Meertens, R.M., van Lange, P.A.M., 1995. Car versus public transportation? The role of social value orientations in a real-life social dilemma. Journal of Applied Social Psychology 25, 258-278.

43. Verplanken, B., Aarts, H., van Knippenberg, A., Knippenberg, C., 1994. Attitude versus general habit: antecedents of travel mode choice. Journal of Applied Social Psychology 24, 285-300.

44. Wedel, M., Kamakura, W.A. (Eds.), 1998. Market Segmentation: Conceptual and Methodological Foundations. Kluwer Academic Publishers, Dordrecht.

45. Zha, H., Ding, C., Gu, M., He, X., \& Simon, H. (2002). Spectral relaxation for K-means clustering. Advances in Neural Information Processing Systems 14 (NIPS'01), $1057-1064$ 